\title{
O CANAL DO LINGUADO DA BAÍA DA BABITONGA/SC: UMA RETROSPECTIVA ATRAVÉS DA HISTÓRIA E CONSIDERAÇÕES SOBRE UMA POSSÍVEL REABERTURA
}

\author{
Fernanda Engel ${ }^{1}$ \\ Renata Falck Storch Böhm ${ }^{2}$ \\ Milena dos Santos Silveira ${ }^{3}$ \\ Ellen Cristina Dell'Agnolo ${ }^{4}$ \\ Marcus Polette 5
}

\begin{abstract}
Resumo: O Canal do Linguado encontra-se fechado definitivamente desde 1935 e este bloqueio trouxe para a região inúmeros problemas. Diante deste cenário, o presente estudo teve por objetivo realizar um levantamento de trabalhos sobre o Canal do Linguado e proceder uma análise e discussão desses dados sob uma perspectiva histórica. A partir de uma análise de dados, os impactos ambientais foram agrupados em meio físico, socioeconômico e biótico. A maioria dos impactos observados foi de natureza negativa ou adversa, e apenas dois foram os impactos considerados positivos em decorrência do fechamento deste Canal. A contribuição deste estudo pautou-se no levantamento de informações sobre o fechamento do Canal do Linguado, assim como evidenciou a falta de estudos específicos nesta área e a falta de correlação destes dados.
\end{abstract}

Palavras-chave: Canal do Linguado; Baía da Babitonga; Impactos Ambientais; Retrospectiva histórica

\section{WATERWAY OF LINGUADO OF BABITONGA/SC BAY/: A RETROSPECTIVE THROUGH THE HISTORY AND CONSIDERATIONS ABOUT A POSSIBLE REOPENING}

\begin{abstract}
The waterway of Linguado is definitely closed since 1935, and this lock brings to the region some problems. Thus, this study aims realize an analysis of secondary studies realized about the waterway of Linguado and make and analysis and discussion this data on a historical perspective. From a data analysis, the environmental impacts were grouped in physical, socioeconomic and biotic environmental. The most of observed impacts were negative or adverse, and only two were considered positive impacts as a result of closing of

\footnotetext{
${ }^{1}$ Doutoranda do Programa de Pós Graduação em Ciência e Tecnologia da Universidade do Vale do ItajaíUNIVALI. Email: fernanda_engel@ hotmail.com

${ }^{2}$ Doutoranda do Programa de Pós Graduação em Ciência e Tecnologia da Universidade do Vale do ItajaíUNIVALI. Email: renatastorch@ hotmail.com

${ }^{3}$ Doutoranda do Programa de Pós Graduação em Ciência e Tecnologia da Universidade do Vale do ItajaíUNIVALI. Email: biomilena@gmail.com

4 Mestranda do Programa de Pós Graduação em Ciência e Tecnologia da Universidade do Vale do ItajaíUNIVALI. Email: ellen.ocenao@ yahoo.com.br

5 Doutor em Ecologia e Recursos Naturais pela Universidade Federal de São Carlos - UFSCar. Email: mpolette@univali.br
} 
this waterway. The contribution of this study was based on survey information about the closed of waterway of Linguado, and evidenced the lack of specific studies in this area, and the lack of the correlation of these data.

Keywords: Waterway of Linguado; Babitonga Bay; Environmental Impacts; Historic retrospective

\section{EL CANAL DEL LENGUADO DE LA BAHÍA DE LA BABITONGA/SC: UNA RETROSPECTIVA A TRAVÉS DE LA HISTORIA Y CONSIDERACIONES SOBRE UNA POSIBLE REAPERTURA}

Resumen: El Canal del Lenguado se encuentra cerrado definitivamente desde 1935 y este bloqueo há traído para la región innumerables problemas. Ante este escenario, el presente estúdio tuvo como objetivo hacer um levantamiento de trabajos sobre el Canal del Lenguado y proceder una análisis y discusión de estos datos desde una perspectiva histórica. A partir de una análisis de datos, lós impactos ambientales se agruparon en medio físico, socioeconômico y biótico. La mayoría de lós impactos observados fue de naturaleza negativa o adversa, y solo dos fueron los impactos considerados positivos en consecuencia del cierre de este Canal. La contribuición de este estúdio se basó en el levantamiento de informaciones sobre el cierre del Canal del Lenguado, así como evidencio la falta de estudios específicos em esta área, y la falta de correlación de estos datos.

Palabras clave: Canal del Lenguado; Bahía de la Babitonga; Impactos Ambientales;

Retrospectiva histórica

\section{INTRODUÇÃO}

\section{ÁREA DE ESTUDO}

O Canal do Linguado está localizado no nordeste do estado de Santa Catarina, (7.329.052,76 E, 7.081.243,14 N, SIRGAS 2000 22J), e sua extensão é de aproximadamente $15 \mathrm{~km}$ (SILVA, 2011) (Figura 1). Um aterro iniciado no ano de 1907 acabou por fechar este canal para que fosse construída uma estrada de ferro, integrando os três estados Sul do país (CRISTOFOLINI et al., 2011). Essa ferrovia atravessaria a Serra Geral de Santa Catarina, passando por Joinville em busca do porto de São Francisco do Sul (BARBOSA, 2003), e naquele ano então, decidiu-se aterrar apenas um dos canais (Norte) e construir uma ponte metálica no outro (Sul). (CRISTOFOLINI et al., 2011). 


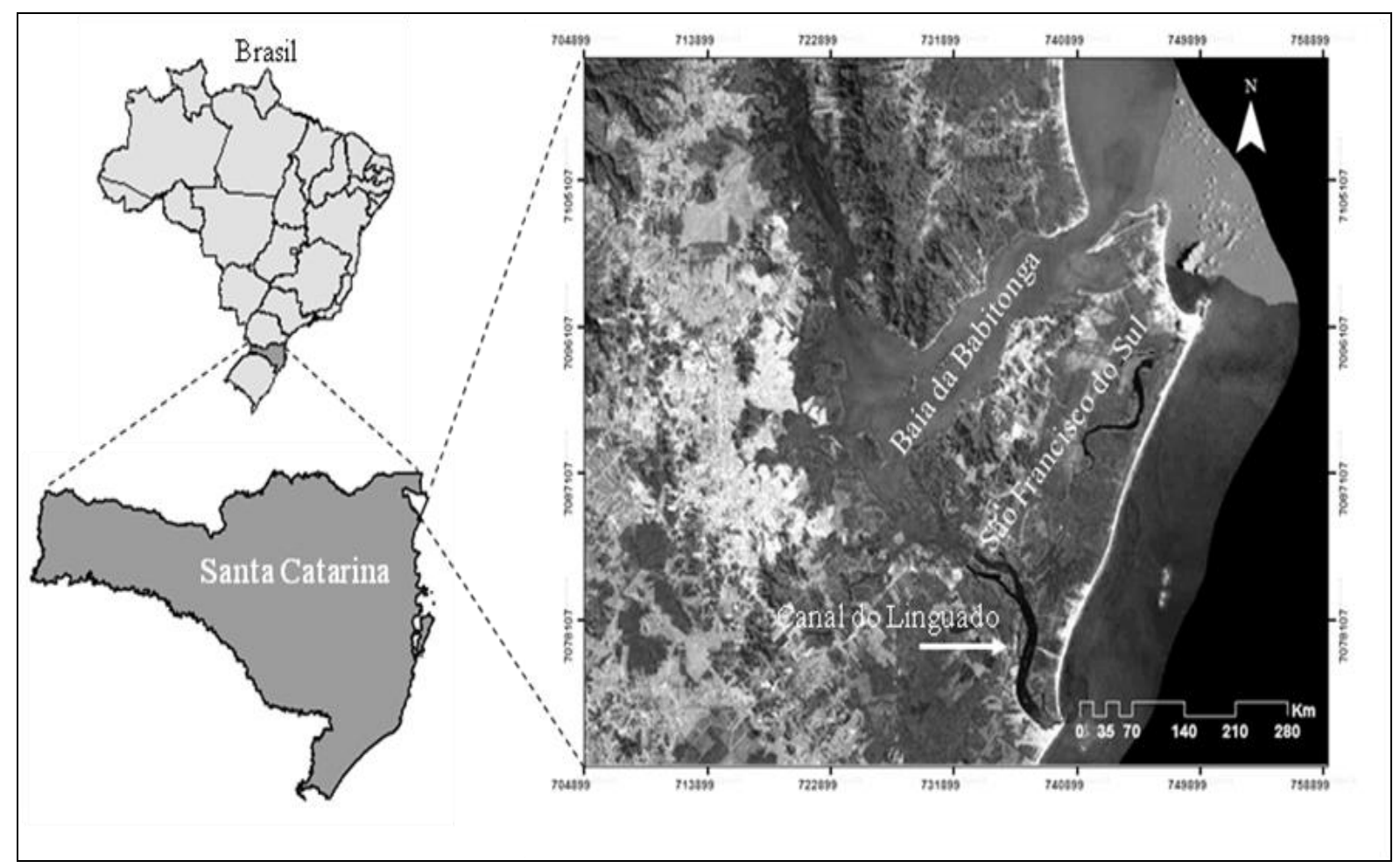

Figura 1: Área de estudo do Canal do Linguado/SC indicado pela flecha, inserido na Baía da Babitonga. Fonte: Arquivo pessoal.

O canal Norte com seus $800 \mathrm{~m}$ de largura foi aterrado, e no canal Sul (Canal do Linguado) com largura de 600m foram construídas duas pontes, uma entre o continente e a então chamada Ilha do Linguado, e outra entre esta e a ilha de São Francisco do Sul. Sete anos mais tarde houve a necessidade de uma intervenção na ponte, uma vez que os pilares de sustentação apresentavam riscos de estabilidade em decorrência da velocidade da água nas vazantes das marés (FERREIRA, 2009, CRISTOFOLINI et al., 2011, SILVA, 2011), e deste modo, optou-se, inicialmente em colocar pedras ao redor dos pilares para melhorar a estabilidade. Sem sucesso com esta medida, em 1934 ocorreu o fechamento completo dos vãos da ponte e após o completo fechamento, em 1935, o aterro possibilitou a ligação viária entre São Francisco do Sul e o continente e também resultou na construção posterior da BR280 (Figura 2) (CREMER et al., 2006; SILVA, 2011), e assim a ilha de São Francisco do Sul acabou tornando-se uma península (CRISTOFOLINI et al., 2011). 


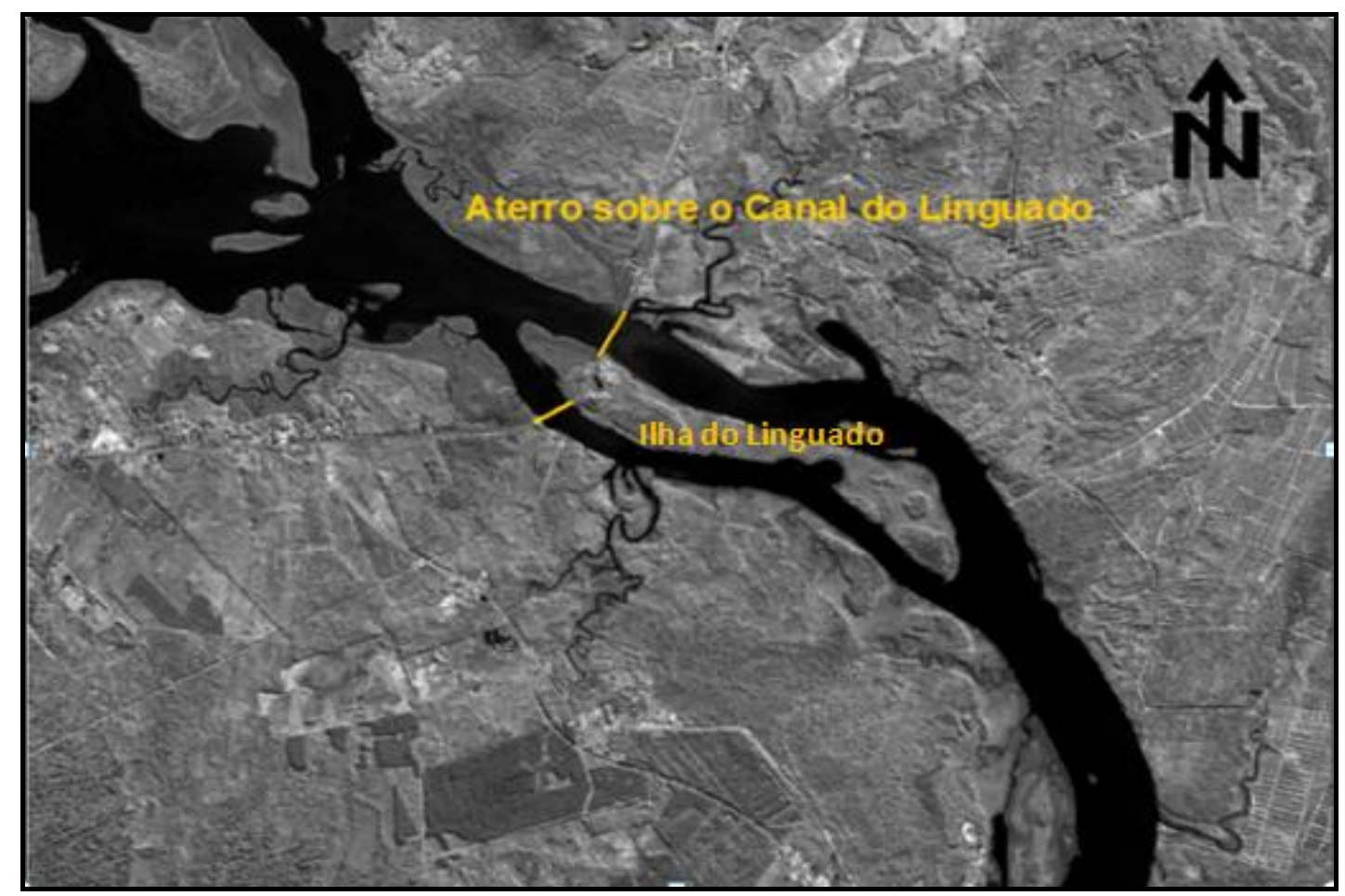

Figura 2: Canal do Linguado com os respectivos aterros Sul e Norte respectivamente, separada pela ilha do Linguado. Fonte: Laboratório de Oceanografia Física - UNIVALI.

Deste modo, o aterro provocou a interrupção hidrodinâmica estabelecida no interior da Baía da Babitonga com o Oceano Atlântico (VIEIRA et. al., 2008, CREMER et. al., 2006), desconsiderando as consequências que a interrupção do fluxo de água poderia causar ao ecossistema marinho, além de ter acumulado ao longo destes 77 anos sedimentos e poluentes dos municípios vizinhos (FATMA, 2002), acarretando em diversos impactos ambientais. Estima-se que anteriormente ao seu fechamento o Canal do Linguado apresentava cerca de $25 \mathrm{~m}$ de profundidade, e atualmente este nível passou a ser de apenas 2 ou 3m, evidenciando a intensa sedimentação sofrida no interior deste Canal, o que provocou problemas relacionados a navegação e a pesca (CREMER et al., 2006; GERHARDINGER, 2007; CRISTOFOLINI et al., 2011).

Assim, este estudo de revisão teve como objetivo realizar uma compilação de 
trabalhos secundários sobre o Canal do Linguado, bem como promover uma discussão sobre os dados levantados por estes autores, demonstrando quais foram os impactos gerados em decorrência do fechamento do Canal, e como os autores se posicionam em relação a uma possível reabertura.

\section{METODOLOGIA}

A metodologia do presente estudo baseou-se em uma compilação a partir de trabalhos realizados no Canal do Linguado e Baía da Babitonga. Os estudos selecionados para discussão foram provenientes de buscas realizadas na internet e em bibliotecas, utilizando como palavras-chaves: Canal do Linguado e Baía da Babitonga. Estas buscas resultaram no agrupamento de diversos documentos tais como: artigos, teses, dissertações, trabalhos de conclusão de curso, estudos apresentados em eventos, livros, entre outros, os quais foram organizados por data e autores.

Os estudos considerados relevantes para a discussão foram obtidos após uma análise e triagem do material, por meio de uma leitura crítica e verificação do atendimento aos parâmetros estabelecidos: a) os impactos positivos e negativos do fechamento do Canal do Linguado; b) comunidades afetadas pelo fechamento deste Canal; c) proposição de mitigação decorrente de seu fechamento; e d) se os autores recomendavam a reabertura do Canal e/ou uma projeção de como seria se este fosse reaberto.

A análise dos dados levantados se fundamentou na técnica da análise de conteúdo de Bardin (2011), utilizada para sistematizar as informações e reduzi-las em categorias de análise, por meio de palavras-chave. A partir desta orientação teórico-metodológica, foi realizada, primeiramente a transcrição dos dados qualitativos, de acordo com os estudos. O passo seguinte foi a agregação destes dados em impactos ao meio Físico, Biótico ou Socioeconômico e por sua vez em categorias teóricas ou temas centrais, a saber: (a) Assoreamento; (b) Contaminação das águas por efluentes agrícolas, industriais e domésticos; (c) Alteração na conformação da desembocadura da barra; (d) Alteração na hidrodinâmica; (e) Obstrução do Canal do Linguado; (f) Degradação da paisagem; (g) Conflito com os 
moradores locais; (h) Ocupação antrópica irregular; (i) Conflitos com a pesca e maricultura; (j) Melhoria em área lazer no Balneário Barra do Sul; (k) Desenvolvimento econômico e (l) Modificação da estrutura das comunidades biológicas. Essas subdivisões englobaram os impactos tanto de caráter positivo quanto negativos, conforme reflexão dos autores deste estudo.

\section{RESULTADOS E DISCUSSÃO}

Segundo a NBR ISO 14001:2004/ABNT Impacto Ambiental é qualquer modificação do meio ambiente, adversa ou benéfica, que resulte, no todo ou em parte, dos aspectos ambientais da organização. É o efeito de uma ação humana sobre o meio ambiente e seus aspectos, a alteração da linha de base por consequência da interferência humana ou eventos naturais. O Impacto pode ser considerado negativo quando o meio é alterado em um sentido de desestabilização prejudicial ao equilíbrio dinâmico dos níveis tróficos, podendo ser quanto à poluição do ar, solo, água e sócio econômico, causando danos à fauna e/ou flora. Ainda, o impacto pode ser positivo, quando, como resultado da alteração do equilíbrio dinâmico, o meio natural se beneficia.

Com base nas 32 pesquisas selecionadas e analisadas foi possível verificar que em apenas 16 delas havia maiores detalhamentos sobre o Canal do Linguado. Dessas pesquisas, procedeu-se o levantamento dos impactos ambientais observados e discutidos pelos autores. Notou-se que grande parte dos impactos ambientais causados pelo fechamento do Canal é de natureza adversa ou negativa, sendo apenas o Desenvolvimento Econômico e a Melhoria em área de lazer para banhistas do Balneário Barra do Sul, considerados impactos benéficos ou positivos. A relação dos impactos ambientais identificados foi descrita no Quadro 1.

Quadro 1: Relação dos impactos ambientais identificados nos documentos analisados.

\begin{tabular}{|c|c|c|}
\hline MEIO & IMPACTOS & AUTORES \\
IMPACTADO & & \\
\hline
\end{tabular}




\begin{tabular}{|c|c|c|}
\hline $\begin{array}{c}\text { MEIO } \\
\text { IMPACTADO }\end{array}$ & IMPACTOS & AUTORES \\
\hline \multirow{5}{*}{ Meio Físico } & Assoreamento & $\begin{array}{l}\text { RODRIGUES (2000); FATMA (2002); } \\
\text { BARBOSA (2003); CREMER et al. (2006); } \\
\text { OLIVEIRA et al. (2006); GERHARDINGER et al. } \\
\text { (2007), VIEIRA et al. (2008); FERREIRA (2009); } \\
\text { SIMM (2009), SILVA (2011), CRISTOFOLINI et } \\
\text { al. (2011); MAZZER e GONÇALVES (2011); } \\
\text { MATTOS (2012) }\end{array}$ \\
\hline & $\begin{array}{l}\text { Contaminação } \\
\text { das águas por } \\
\text { efluentes } \\
\text { agrícolas, } \\
\text { industriais e } \\
\text { domésticos }\end{array}$ & $\begin{array}{c}\text { RODRIGUES (2000); FATMA (2002); } \\
\text { OLIVEIRA et al. (2006), VIEIRA et al. (2008); } \\
\text { DEMORI (2008), FERREIRA (2009); SIMM } \\
\text { (2009), BARROS et al (2010), CRISTOFOLINI et } \\
\text { al. (2011); MATTOS (2012); MARTINS et al. } \\
\text { (2014) }\end{array}$ \\
\hline & $\begin{array}{l}\text { Alteração na } \\
\text { conformação da } \\
\text { desembocadura } \\
\text { da barra Sul }\end{array}$ & $\begin{array}{l}\text { BARBOSA (2003); CREMER et al. (2006); } \\
\text { FERREIRA (2009), MAZZER e GONÇALVES } \\
(2011)\end{array}$ \\
\hline & $\begin{array}{l}\text { Alteração na } \\
\text { hidrodinâmica }\end{array}$ & $\begin{array}{l}\text { RODRIGUES (2000); FATMA (2002); CREMER } \\
\text { et al. (2006); OLIVEIRA et al. (2006); } \\
\text { GERHARDINGER et al. (2006); VIEIRA et al. } \\
\text { (2008); FERREIRA (2009); SIMM (2009); } \\
\text { MAZZER e GONÇALVES (2011); SILVA (2011) } \\
\text { MATTOS (2012) }\end{array}$ \\
\hline & $\begin{array}{l}\text { Obstrução do } \\
\text { Canal do } \\
\text { Linguado }\end{array}$ & SIMM (2009); CRISTOFOLINI et al. (2011) \\
\hline \multirow{3}{*}{$\begin{array}{c}\text { Meio } \\
\text { Socioeconômico }\end{array}$} & $\begin{array}{l}\text { Degradação da } \\
\text { paisagem }\end{array}$ & CRISTOFOLINI et al. (2011) \\
\hline & $\begin{array}{l}\text { Conflito com os } \\
\text { moradores locais }\end{array}$ & $\begin{array}{c}\text { FERREIRA (2009); CRISTOFOLINI et al. (2011); } \\
\text { MATTOS (2012) }\end{array}$ \\
\hline & $\begin{array}{l}\text { Ocupação } \\
\text { antrópica } \\
\text { irregular }\end{array}$ & $\begin{array}{l}\text { RODRIGUES (2000); BARBOSA (2003); } \\
\text { CRISTOFOLINI et al. (2011) }\end{array}$ \\
\hline
\end{tabular}




\begin{tabular}{|c|c|c|}
\hline $\begin{array}{c}\text { MEIO } \\
\text { IMPACTADO }\end{array}$ & IMPACTOS & AUTORES \\
\hline \multirow{1}{*}{$\begin{array}{c}\text { Conflitos com a } \\
\text { pesca e } \\
\text { maricultura }\end{array}$} & FERREIRA (2009); SIMM (2009) \\
\cline { 2 - 3 } & $\begin{array}{c}\text { Desenvolvimento } \\
\text { Econômico }\end{array}$ & RODRIGUES (2000); CRISTOFOLINI et al. \\
& $\begin{array}{c}\text { Melhoria em área } \\
\text { de lazer para } \\
\text { banhistas no } \\
\text { Balneário Barra } \\
\text { do Sul }\end{array}$ & SILVA (2011) \\
\hline \multirow{2}{*}{ Meio Biótico } & $\begin{array}{c}\text { Modificação da } \\
\text { estrutura das } \\
\text { comunidades } \\
\text { biológicas }\end{array}$ & CRISTOFOLINI et al (2011); MATTOS (2012). \\
\hline & \\
\hline
\end{tabular}

Os impactos ambientais resultantes do fechamento do Canal para a construção da estrada foram enquadrados de acordo com o meio impactado, sendo eles: meio físico, meio socioeconômico e meio biótico.

\section{Impactos no Meio Físico}

Quanto aos impactos no meio físico destacaram-se o assoreamento, a contaminação das águas, as alterações na desembocadura, as alterações na hidrodinâmica e obstrução do Canal do Linguado.

O gradativo assoreamento reduziu a profundidade do Canal (CREMER et al, 2006; SILVA, 2011; MAZZER e GONÇALVES, 2011), formou bancos de areia no seu interior e próximo à desembocadura do canal (BARBOSA, 2003; FERREIRA, 2009) e propiciou na área adjacente ao aterro na parte interna da Baía a deposição de lodo (VIEIRA et al., 2008; 
SIMM, 2009), além de expor amplas planícies de marés (MAZZER e GONÇALVES, 2011).

Estudos apontaram diferentes fontes de contaminação da água do canal, como poluentes advindos de efluentes industriais e domésticos (DEMORI, 2008; VIEIRA et al., 2008; BARROS et al, 2010; CRISTOFOLINI et al., 2011; MATTOS, 2012; MARTINS, 2014) e defensivos agrícolas (RODRIGUES, 2000). Dados mostraram níveis de metais e microbiológicos acima dos limites legais (OLIVEIRA et al., 2006; DEMORI, 2008), além de indicativos da contaminação por Coprostanol na parte sul da Baía da Babitonga, sendo este um esterol encontrado nas fezes humanas, evidenciando a contaminação pelo esgoto, bem como a presença de Alquilbenzenos, matéria prima utilizada para a produção de surfactantes aniônicos, usados largamente na manufatura de detergentes de uso doméstico, tornando ambos marcadores de contaminação em ambientes marinhos, o que trás dados suficientes para justificar uma política ambiental forte para esta região (MARTINS et al., 2014).

O fechamento do Canal do Linguado associado às ações das ondas ocasionou muitas alterações na desembocadura da barra. Notou-se o desaparecimento de um baixio na região antelitoral (BARBOSA, 2003) e a formação de bancos sedimentares sugerindo a presença de delta deposicional (MAZZER; GONÇALVES, 2011), o que levou a mudança de delta estuarino para delta lacunar devido ao baixo aporte fluvial (BARBOSA, 2003). Além disso, houve um processo de obstrução da barra em Barra do Sul (CREMER et al., 2006; FERREIRA, 2009), formação de um esporão arenoso na desembocadura do canal e ocorrência de uma migração da desembocadura em direção nordeste (BARBOSA, 2003).

Além dos problemas com a desembocadura da barra, ocorreram alterações na hidrodinâmica do canal. A redução na circulação das águas (RODRIGUES, 2000; CREMER et al., 2006; OLIVEIRA et al., 2006; SIMM, 2009; SILVA, 2011) alterou os canais preferenciais de circulação e de colmatagem (VIEIRA et al., 2008), além de se verificar a inversão da direção da vazão dos afluentes na maré alta, trazendo poluentes aos seus locais de origem (FATMA, 2002; GERHARDINGER et al., 2006; FERREIRA, 2009; SIMM, 2009; MAZZER; GONÇALVES, 2011). Tais modificações provocaram mudanças drásticas nos padrões de altura da coluna d’água (MATTOS, 2012) e reduziram a área de drenagem total da Baía (OLIVEIRA et al., 2006), comprometendo toda a hidrodinâmica de todo o sistema estuarino (CREMER et al., 2006). 
O impacto causado pela obstrução do Canal do Linguado, transformou a ilha de São Francisco do Sul em uma península (CRISTOFOLINI et al., 2011) e a parte do canal isolada (em Barra do Sul) assemelha-se a uma lagoa costeira (SIMM, 2009).

Os impactos no meio físico se conectam, à medida que um torna-se o fator desencadeador do outro. A obstrução do Canal do Linguado causou a alteração da hidrodinâmica, que ocasionou alterações morfodinâmicas da barra Sul, da mesma forma a alteração hidrodinâmica desencadeou um processo de assoreamento na parte interna do canal, criando um ambiente mais estático, com menor fluxo de renovação de água ficando este ambiente mais suscetível à contaminação das águas por efluentes agrícolas, industriais e domésticos.

\section{Impactos no Meio Socioeconômico}

Os impactos ambientais no meio socioeconômico apresentaram relação com a degradação da paisagem, conflito com os moradores locais, ocupação antrópica irregular, conflitos com a pesca e maricultura, desenvolvimento econômico e a melhoria em área de lazer para banhistas no Balneário Barra do Sul.

A degradação da paisagem trouxe redução nos passeios de barco no local e prejuízos em relação ao turismo no Canal do Linguado (CRISTOFOLINI et al., 2011). A formação de lodo e a exposição do fundo síltico-argiloso, ambos mal cheirosos (FERREIRA, 2009; CRISTOFOLINI et al., 2011), geraram conflitos com os moradores locais. Somando-se a esses fatores, casos de micoses começaram a ser relatados pela comunidade (CRISTOFOLINI et al., 2011; MATTOS, 2012), bem como o declínio dos atrativos econômicos e sociais (MATTOS, 2012).

Na região próxima a desembocadura há ocupação humana em áreas que, anteriormente ao fechamento do Canal eram submetidas à inundação natural (RODRIGUES, 2000; BARBOSA, 2003; CRISTOFOLINI et al., 2011), revelando sérios problemas de ocupação antrópica irregular. 
Um dos grupos sociais que foi fortemente impactado com o fechamento do Canal do Linguado foi os pescadores artesanais, e em menor proporção os maricultores, haja vista as poucas áreas de aquicultura no interior da Baía da Babitonga (FERREIRA, 2009). Foram dois os impactos principais sofridos pelas comunidades pesqueiras lindeiras ao aterro: um deles foi a redução na produtividade pesqueira devido às alterações hidrodinâmicas do local, ocasionando a redução na fonte de sustento de comunidades locais que dependiam da pesca (FERREIRA, 2009), e o outro foi a impossibilidade de navegação, pois, a diminuição da profundidade do Canal ocasionada pelo assoreamento não permite embarcações a remo em marés baixas (SIMM, 2009). Nestas circunstâncias, os pescadores com embarcações pequenas e motores pouco potentes só podem se movimentar nas horas de maré cheia, o que acaba restringindo bastante a sua área de atuação de pesca, ficando limitados à porção sudoeste da Baía da Babitonga.

A redução da maricultura se explica pelo fato desta atividade requer águas abrigadas, porém com fluxo constante de água, profundidade adequada e certamente boa qualidade de água, itens estes comprometidos desde o fechamento do Canal.

Os dois aspectos positivos relatados por alguns dos trabalhos analisados foram: o desenvolvimento econômico (RODRIGUES, 2000; CRISTOFOLINI et al., 2011) e a formação de um local com águas mais abrigadas servindo de local para banhistas em Balneário Barra do Sul (SILVA, 2011). Quanto ao desenvolvimento econômico os impactos advêm do próprio objetivo do fechamento do Canal do Linguado, sendo a questão econômica a mola propulsora desta obra. Com as obras de construção da rodovia e ferrovia, consolidadas após o fechamento do Canal foi possível atender o escoamento de mercadorias e consequentemente gerou desenvolvimento não só para o Porto (RODRIGUES, 2000), como para toda a sua cadeia produtiva, pois o novo acesso facilitou a logística do Porto de São Francisco do Sul (CRISTOFOLINI et al., (2011).

Com a ausência de fluxos hidrodinâmicos, formou-se uma espécie de laguna em Balneário Barra do Sul, e Silva (2011) relatou que uma vantagem do fechamento foi que houve uma conformação neste local de uma nova área de lazer, com águas mais calmas proporcionando a presença de banhistas, sendo estes um dos poucos pontos positivos elencados pelos trabalhos analisados. Ressalta-se que, a área de laguna formada deve ser 
monitorada para assegurar a balneabilidade deste local e garantir a saúde e o bem-estar dos banhistas e turistas.

As interconexões dos impactos ocorrem primordialmente no meio físico, estes acabam interagindo com o meio socioeconômico, a exemplo da degradação da paisagem que é oriunda do processo de assoreamento. Já a ocupação irregular ocorre em decorrência da obstrução do canal, que alterou a hidrodinâmica local, deixando os leitos do canal expostos, criando uma faixa marginal, aumentando o território de solo exposto, que embora impróprio, passou a ser ocupado.

De forma indireta os impactos negativos socioeconômicos se relacionam, pois, a degradação da paisagem, o conflito com os moradores locais, a ocupação antrópica irregular e os conflitos com a pesca e maricultura todos têm a mesma origem, o assoreamento, ainda que estes não sejam cadenciados. De forma semelhante os impactos positivos: desenvolvimento econômico e melhoria em área de lazer para banhistas no Balneário Barra do Sul não se relacionam, porém, são consequência da mesma alteração, a obstrução do canal do Linguado.

\section{Impactos no Meio Biótico}

A alteração no meio biótico foi descrita como modificação da estrutura das comunidades biológicas (MATTOS, 2012). O fechamento do Canal e consequente assoreamento causaram alterações em sua batimetria, e em decorrência disso, o soterramento dos organismos que habitam o substrato inconsolidado, a exemplo de invertebrados bentônicos. Cristofolini e colaboradores (2011) foram mais específicos e ressaltaram que as alterações do fechamento do Canal do Linguado causaram impactos negativos, podendo ocasionar mortes de espécies da biota local, principalmente da ictiofauna.

Dentro de uma perspectiva histórica, foi possível perceber que no período de 2000 a 2014 as primeiras publicações foram voltadas às análises dos impactos causados no meio físico, sendo que em apenas 2009 começaram os estudos para o meio socioeconômico. 
Somente em $25 \%$ das pesquisas analisadas foram sugeridas proposições de mitigação para os impactos decorrentes do fechamento do canal, tais como monitoramento, fiscalização, recuperação e manutenção das áreas afetadas.

Outro parâmetro analisado nas pesquisas selecionadas foi o levantamento das comunidades afetadas pelo fechamento do Canal do Linguado. Notou-se que apenas 37,5\% dos trabalhos citam diretamente quais foram essas comunidades atingidas, sendo os pescadores os mais mencionados, seguidos dos moradores e ribeirinhos.

Por fim, constatou-se que $87,5 \%$ dos autores não citam ou não se posicionam quanto à reabertura do Canal do Linguado. Além disso, os que sugerem que o canal seja reaberto não apresentam embasamento técnico, mas ressaltam que esta reabertura seria uma restauração a longo prazo.

\section{CONSIDERAÇÕES FINAIS}

Com base no exposto neste estudo foi possível identificar que a maioria dos impactos gerados em decorrência do fechamento do Canal do Linguado é de natureza negativa, considerando-se apenas dois os impactos positivos gerados por este fechamento. Através dos dados levantados verifica-se que a maioria dos autores pesquisados não se posiciona em relação a abertura do Canal do Linguado, e os que acabam por citar carecem de maiores informações técnicas e correlacionadas com os impactos decorrentes de uma reabertura. São poucos também os trabalhos que citam as comunidades diretamente atingidas pelo fechamento do Canal, pautando-se muitas vezes em apenas estudar o que ocorre na região, sem fazer relações com estudos passados e previsões futuras. Espera-se que novos estudos sejam realizados no Canal do Linguado, e que estes estejam relacionados com os impactos da implementação do Canal, bem como que sejam realizados estudos de correlação dos impactos nos meios físico, socioeconômico e biótico, para que assim seja possível melhorar o entendimento e propor medidas mitigadoras em decorrência de seu fechamento. 


\section{REFERENCIAS}

BARBOSA, A. Mudanças geomorfológicas ocorridas na desembocadura no sul do canal do Linguado no período de 1938-1989. Revista da Univille, v. 9, n. 1, p. 117-124, 2003.

BARDIN, L. Análise de conteúdo. São Paulo: Edições 70, 2011. 280 p.

BARROS, G. V.; MARTINELLI L. A.; OLIVEIRA, T. M. N.; OMETTO, J. P.; ZUPPI, G. M. Stable isotopes of bulk organic matter to trace carbon and nitrogen dynamics in an estuarine ecosystem in Babitonga Bay (Santa Catarina, Brazil). The Science of the Total Environmental, v. 10, n. 408, p. 2226-2232, 2010.

CREMER, M. J.; GROSE, A. V. Ocorrência de aves marinhas no estuário da Baía da Babitonga, costa norte de Santa Catarina, sul do Brasil. Revista Brasileira de Ornitologia, v. 18, n. 3, p. 176-182, 2010.

CREMER, M. J.; MORAES, P. R. D.; OLIVEIRA, T. M. N. Diagnóstico Ambiental da Baía da Babitonga. Joinville: UNIVILLE. 2006. 256 p.

CRISTOFOLINI, L.; FOGLIATTO, M. M.; MOREIRA, M. E. Análise socioambiental do fechamento do canal do Linguado/SC. Revista Geográfica de América Central, v. 2, n. 47E, p. 1-8, 2011.

DEMORI, J. Análise histórica da contaminação por metais pesados na baía da Babitonga-SC. 2008. 94 f. Dissertação (Mestrado em ciência e tecnologia ambiental) Universidade do Vale do Itajaí, Itajaí. 2008.

FATMA - Fundação do Meio Ambiente de Santa Catarina. Atlas Ambiental da Região de Joinville: Complexo Hídrico da Baía da Babitonga. Florianópolis: FATMA, 2002. 144 p.

FERREIRA, M. L. A. Estudo dos aspectos negativos causados ao meio ambiente pelo fechamento do canal do Linguado no ecossistema estuarino da Baía da Babitonga/Canal do Linguado. 2009. 58p. Monografia (Bacharelado em Gestão Ambiental) - Universidade Candido Mendes, Rio de Janeiro. 2009.

GERHARDINGER, L. C.; MARENZI, R. C.; SILVA, M. H.; MEDEIROS, R. P. Conhecimento ecológico local de pescadores da Baía Babitonga, Santa Catarina, Brasil: peixes da família Serranidae e alterações no ambiente marinho. Acta Scientiarum. Biological Sciences, v. 28, n. 3, p. 253-261, 2007.

IBAMA. Proteção e controle de ecossistemas costeiros: manguezal da Baía da Babitonga. Instituto Brasileiro do Meio Ambiente e dos Recursos Naturais Renováveis. Brasília: IBAMA, 1998.

MARTINS, C. C.; CABRAL, A. C.; CINTRA-BARBOSA, C. T.; DAUNER, A. L. L.; SOUZA, F. M. An integrated evaluation of molecular marker indices and linear alkylbenzenes (LABs) to measure sewage input in a subtropical estuary (Babitonga Bay, Brazil). Environmental Pollution, v. 188, p. 71-80, 2014.

MATOS, J. A. D. Caracterização Hidrodinâmica da Baia da Babitonga antes do fechamento parcial e total do canal do linguado utilizando modelagem numérica computacional, SC Brasil. 2012. 99 f. Monografia (Graduação em Oceanografia) Universidade do Vale do Itajaí, Itajaí. 2012.

MAZZER, A. M.; GONÇALVES, M. L. Aspectos Geomorfológicos da Baía da Babitonga, Santa Catarina, Brasil: Caracterização Morfométrica. Revista Brasileira de Geomorfologia, v. 12, n. 3, p. 115-120, 2011.

OLIVEIRA, F. A. Estudo do aporte sedimentar em suspensão na Baía da Babitonga sob a ótica da geomorfologia. 2006. 286 f. Tese (Doutorado em Geografia Física) - Faculdade de 
Filosofia, Letras e Ciências Humanas da Universidade de São Paulo, São Paulo. 2006.

RIDD, P. V.; STIEGLITZ, T. Dry season salinity changes in arid estuaries fringedby mangroves and saltflats. Estuarine, Coastal and Shelf Science, v. 54, p. 1039-1049, 2002.

RODRIGUES, A. M. T. Diagnóstico socioeconômico e a percepção ambiental das comunidades de pescadores artesanais do entorno da Baía da Babitonga (SC): um subsídio ao gerenciamento costeiro. 2000. 233 f. Dissertação (Mestrado em Engenharia Ambiental) - Universidade Federal de Santa Catarina, Florianópolis. 2000.

SILVA, L. F. Alterações morfodinâmicas do Canal do Linguado pela remoção do dique que o separa da Baía da Babitona-SC. 2011. 198p. Tese (Doutorado em Geociências) Universidade Federal do Rio Grande do Sul, Rio Grande do Sul. 2011.

SIMM, M. Avaliação da qualidade da água em amostras provenientes da Baía da Babitonga-SC, através de ensaios de embriotoxicidade e de exposição prolongada ao ar, utilizando mexilhão da espécie Perna perna (Linnaeus, 1758) na fase larval e adulta. 2009. 107 f. Dissertação (Mestrado em Saúde e Meio Ambiente) - Universidade da Região de Joinville. 2009.

TWILLEY R. R.; SNEDAKER R, R.; YÁÑEZ-ARANCIBIA S. C.; MEDINA A. Biodiversity and ecosystem processes in tropical estuaries: perspectives of mangrove ecosystems. In: MOONEY, H. A.; CUSHMAN, J. H.; MEDINA, E.; SALA, O. E.; SCHULZE, E. D (Ed.). Functional Roles of Biodiversity: a Global Perspective. New York: Wiley, 1996. p. 327-370.

VIEIRA, C. V.; HORN FILHO, N. O.; BONETTI, C. V. D. H. C.; BONETTI, J. Caracterização morfosedimentar e setorização do complexo estuarino da Baía da Babitonga/SC. Boletim Paranaense de Geociências, n. 62-63, p. 85-105, 2008.

Recebido em outubro de 2016.

Aceito em junho de 2017. 